Kumawula, Vol. 3, No.3, Desember 2020, Hal 435 - 440 DOI: https://doi.org/10.24198/kumawula.v3i3.28025

ISSN 2620-844X (online)

Tersedia online di http://jurnal.unpad.ac.id/kumawula/index

\title{
PENYULUHAN KONSUMSI PANGAN LOKAL UNTUK PENDERITA DIABETES MELITUS DI DESA DILEM, KEPANJEN, MALANG
}

\author{
Yahmi Ira Setyaningrum ${ }^{1}$, Choirun Nissa ${ }^{2}$ \\ ${ }^{1}$ S1 Ilmu Gizi, STIKes Widya Cipta Husada, Malang \\ ${ }^{2}$ S1 Ilmu Gizi, STIKes Widya Cipta Husada, Malang \\ *Korespondensi: rasetyrum@yahoo.co.id
}

\begin{abstract}
Diabetes is a non-communicable disease (PTM) that is often suffered by the people of Indonesia. One of the causes of diabetes mellitus (DM) is a bad lifestyle and consumption patterns. Based on this, an effort is needed to educate local food consumption for diabetics in Dilem Village, Kepanjen, Malang. The purpose of counseling is to increase Dilem Village people's knowledge about diabetes mellitus and prevention efforts through local food consumption. Counseling method with lectures, using leaflet media. The results of this counseling program were able to increase Dilem's village community knowledge about the importance of maintaining a healthy diet, local food consumption patterns to avoid complications of diabetes mellitus by 50\%. Conclusions that can be drawn need further research to find out attitudes and behavior of people who have increased knowledge of diabetes mellitus.
\end{abstract}

\begin{abstract}
ABSTRAK
Penyakit diabetes adalah salah satu penyakit tidak menular (PTM) yang sering diderita oleh masyarakat Indonesia. Salah satu penyebab diabetes melitus (DM) adalah gaya hidup dan pola konsumsi yang kurang baik. Berdasarkan hal tersebut diperlukan suatu upaya penyuluhan konsumsi pangan lokal untuk penderita diabetes di desa Dilem, Kepanjen, Malang. Tujuan penyuluhan adalah untuk meningkatkan pengetahuan masyarakat desa Dilem mengenai diabetes melitus dan upaya pencegahan melalui konsumsi pangan lokal. Metode penyuluhan dengan ceramah, menggunakan media leaflet. Hasil program penyuluhan ini mampu meningkatkan pengetahuan masyarakat desa Dilem mengenai pentingnya menjaga pola makan, pola konsumsi pangan lokal agar terhindar dari komplikasi penyakit diabetes melitus sebesar 50\%. Kesimpulan yang dapat diambil perlu penelitian lebih lanjut untuk mengetahui sikap dan perilaku masyarakat yang telah meningkat pengetahuannya akan diabetes melitus.
\end{abstract}

Keywords: diabetes; penyuluhan; konsumsi; pangan.

\section{PENDAHULUAN}

Diabetes melitus merupakan salah satu penyakit tidak menular (PTM) yang disebabkan oleh gangguan metabolik. Gangguan metabolik yang disebabkan kelainan sekresi insulin sehingga produksi insulin menurun. Hormon insulin berfungsi untuk mengubah glukosa (gula darah) menjadi glikogen. Produksi insulin yang menurun mengakibatkan gula darah meningkat atau disebut hiperglikemia. Penyakit diabetes melitus seringkali disebut penyakit masyarakat, karena jumlah penderitanya sangat banyak. Hal ini didukung dari data, diperkirakan bahwa pada tahun 2030 prevalensi
Diabetes Melitus (DM) di Indonesia mencapai 21,3 juta orang atau sekitar 9,5\%. Riset Kesehatan Dasar (Riskesdas) memperlihatkan peningkatan angka prevalensi Diabetes yang cukup signifikanyaitu dari 6,9\% di tahun 2013 menjadi 8,5\% di tahun 2018. Hasil Riskesdas 2007 prevalensi nasional DM berdasarkan pemeriksaan gula darah pada penduduk usia $>15$ tahun diperkotaan 5,7\%. Prevalensi nasional Obesitas umum pada penduduk usia > 15 tahun sebesar $10.3 \%$ dan sebanyak 12 provinsi memiliki prevalensi diatas nasional, serta untuk prevalensi nasional Obesitas sentral pada penduduk Usia > 15 tahun sebesar 18,8\% dan sebanyak 17 provinsi memiliki prevalensi 
diatas nasional. Sedangkan prevalensi TGT (Toleransi Glukosa Terganggu) pada penduduk usia $>15$ tahun di perkotaan adalah $10.2 \%$ dan sebanyak 13 provinsi mempunyai prevalensi diatas prevalensi nasional. Prevalensi kurang makan buah dan sayur sebesar 93,6\%, dan prevalensi kurang aktivitas fisik pada penduduk $>10$ tahun sebesar 48,2\%. Disebutkan pula bahwa prevalensi merokok setiap hari pada penduduk >10 tahun sebesar $23,7 \%$ dan prevalensi minum beralkohol dalam satu bulan terakhir adalah $4,6 \%$.

Tingginya prevalensi diabetes melitus harus segera diatasi, mengingat prevalensi sangat tinggi dan penyakit ini tergolong silent killer. Hal ini didukung dari data Riset kesehatan Dasar (Riskesdas) tahun 2007, menyatakan bahwa proporsi penyebab kematian akibat DM pada kelompok usia 45-54 tahun di daerah perkotaan menduduki ranking ke-2 yaitu $14,7 \%$. Pada daerah pedesaan, DM menduduki ranking ke-6 yaitu 5,8\%. Penyakit ini membutuhkan perhatian dan perawatan medis dalam waktu lama baik untuk mencegah komplikasi maupun perawatan sakit. Diabetes Melitus terdiri dari dua tipe yaitu tipe pertama DM yang disebabkan keturunan dan tipe kedua disebabkan life style atau gaya hidup. Secara umum, hampir $80 \%$ prevalensi diabetes melitus adalah DM tipe 2. Ini berarti gaya hidup/life style yang tidak sehat menjadi pemicu utama meningkatnya prevalensi DM. Bila dicermati, penduduk dengan obes mempunyai risiko terkena DM lebih besar dari penduduk yang tidak obes.

WHO merekomendasikan bahwa strategi yang efektif perlu dilakukan secara terintegrasi, berbasis masyarakat melalui kerjasama lintas program dan lintas sektor termasuk swasta. Pengembangan kemitraan dengan berbagai unsur di masyarakat dan lintas sektor yang terkait dengan DM di setiap wilayah merupakan kegiatan yang penting dilakukan. Berdasarkan hal tersebut, Program Studi S1 Ilmu Gizi berkomitmen untuk turut serta dalam memberi pemahaman faktor risiko DM sangat penting diketahui, dimengerti dan dapat dikendalikan oleh pendidik (dosen) dan mahasiswa maupun kader kesehatan di masyarakat sekitarnya. Program yang dipilih melalui kegiatan penyuluhan kepada masyarakat mengenai diabetes dengan media leaflet. Leaflet merupakan salah satu media untuk menyampaikan pesan atau pendidikan kesehatan dalam bentuk cetak. Adapun pesan kesehatan tentang diabetes yang disampaikan melalui leaflet antara lain gambaran umum diabetes melitus, tujuan diet, makanan yang baik dimakan, makanan yang perlu dibatasi, pengaturan diet, pedoman diet, macam diet.

Tujuan kegiatan pengabdian masyarakat ini untuk meningkatkan pemahaman masyarakat terhadap DM untuk mencegah kasus DM di masyarakat. Harapannya dengan tingkat pemahaman/pengetahuan yang baik, masyarakat akan melakukan perilaku kesehatan untuk pencegahan penyakit, sehingga angka kesakitan, kecacatan dan kematian yang disebabkan DM menurun. Pengendalian DM lebih diprioritaskan pada pencegahan dini melalui upaya pencegahan faktor risiko DM yaitu upaya promotif dan preventif. Diabetes Melitus merupakan ancaman global dan serius sebagai salah satu penyakit tidak menular yang menitikberatkan pada pencegahan penyakit

Permasalahan yang dihadapi oleh Mitra berdasarkan data dari Desa Dilem tahun 2018 antara lain angka kejadian diabetes merupakan yang kedua setelah hipertensi, komplikasi makro maupun mikrovaskuler yang kerap terjadi pada penderita diabetes mellitus, penderita diabetes di Desa Dilem sudah banyak yang berobat ke puskesmas, dan mendapat pengetahuan tentang pola makan penderita diabetes, namun edukasi yang diberikan kepada masyarakat ini perlu berkelanjutan mengingat tingginya angka kejadian penyakit ini. Solusi yang ditawarkan adalah melalui pemberian edukasi gizi melalui pemanfaatan pangan lokal masyarakat untuk penderita diabetisi

\section{METODE}

Kegiatan pengabdian masyarakat dilakukan di Desa Dilem, Kecamatan Kepanjen, Kabupaten Malang, Jawa Timur pada bulan AgustusSeptember 2019. Latar belakang peserta 25 
orang warga Dilem dengan rincian 20 orang berjenis kelamin perempuan, dengan profesi Ibu Rumah Tangga dan 5 orang berjenis kelamin laki-laki (dengan profesi Ketua Takmir Masjid Al Hidayah, Bapak RT dan masyarakat). Program pengabdian kepada masyarakat berupa edukasi kepada masyarakat untuk (1) memberikan pendidikan berkelanjutan tentang gejala, faktor risiko dan komplikasi diabetes (2) memberikan pendidikan berkelanjutan tentang syarat diet diabetes dan pangan yang boleh dikonsumsi terutama pangan lokal; dan (3) memberikan pendidikan berkelanjutan tentang makanan yang tidak boleh dikonsumsi. Media yang digunakan untuk edukasi yaitu leaflet.

Metode pelaksanaan pendidikan berkelanjutan terdiri dari tahapan perkenalan, pre-test, pemberian materi dan media edukasi dengan metode ceramah, diskusi dan tanya jawab, post-test dan diakhiri dengan penutup. Beberapa strategi yang dilakukan agar program penyuluhan dapat berjalan dengan baik, maka antara lain upaya promotif berupa penyuluhan kepada masyarakat, tokoh masyarakat antara lain mengenai gejala, faktor risiko dan komplikasi diabetes, prinsip dan syarat diet
Makanan lokal yang dianjurkan dimakan oleh penderita DM antara lain nasi, telur, tempe, buncis, sayur, pepaya, tongkol, kentang. Makanan yang perlu dibatasi yaitu sumber karbohidrat. Karbohidrat seperti nasi, kentang, ketan, lontong, mie, ubi, talas, sagu, makaroni, dan makanan berbahan dasar tepung. Makanan yang tidak boleh dimakan adalah semua makanan yang diolah dengan gula murni. Makanan tersebut antara lain gula pasir, gula batu, gula jawa, madu, dodol, cake, dendeng manis, selai, susu kental manis, kue-kue manis, sirup, biskuit, abon manis dan kecap manis.

Pengaturan diet meliputi makan teratur sesuai jumlah dan pembagian porsi, gunakan daftar bahan makanan penukar untuk memilih makanan yang disukai dan menyesuaikan dengan menu keluarga, nikmati makanan, tetapi mengingat jenis, jumlah dan jadwal. Jenis makanan yang manis harus dihindari. Jadwal diet harus diikuti sesuai dengan interval yaitu 3 jam. Tepat jumlah artinya jumlah energi yang dimakan sesuai pedoman. Pengaruh pendidikan kepada masyarakat melalui penyuluhan tentang pencegahan diabetes dengan pemanfaatan pangan lokal terlihat pada Tabel 1 .

\section{Tabel 1 Hasil Pre Tes dan Post Tes Pengetahuan Masyarakat Dilem}

$\begin{array}{lcccc}\text { Perlakuan } & \text { N } & \text { Rata-rata pre tes } \pm \text { SD } & \text { Rata-rata post tes } \pm \text { SD } & \text { F } \\ \text { Penyuluhan } & 25 & 47,80 \pm 8,78 & 84,80 \pm 7,14 & 0,00\end{array}$

Sumber: Pengolahan data primer

diabetes serta pangan yang boleh dikonsumsi terutama pangan lokal, makanan yang tidak boleh dikonsumsi

\section{HASIL DAN PEMBAHASAN}

\section{Isi Hasil dan Pembahasan}

Diabetes melitus (DM) merupakan kumpulan gejala akibat peningkatan kadar glukosa dalam darah, yang diakibatkan oleh kurangnya hormon insulin dalam tubuh. Tujuan dari diet penderita DM antara lain menurunkan kadar glukosa dalam darah sehingga menjadi normal, menurunkan kadar kolesterol dalam darah, mencapai berat badan normal, dan melakukan pekerjaan sehari-hari seperti biasanya.
Rata-rata tes pengetahuan sebelum penyuluhan adalah 47,80, sedangkan rata-rata tes pengetahuan setelah penyuluhan adalah adalah 84,80 . Berdasarkan hal tersebut dapat disimpulkan bahwa penyuluhan dengan metode ceramah dapat meningkatkan skor pengetahuan masyarakat tentang DM sebanyak 37. Penyuluhan memberikan hasil yang signifikan terhadap tingkat pengetahuan masyarakat mengenai gambaran umum penyakit DM, tujuan diet DM, faktor penyebab DM, penyakit komplikasi yang dapat ditimbulkan oleh DM, pangan lokal yang dapat dikonsumsi oleh penderita DM serta makanan yang tidak boleh dimakan, makanan yang perlu dibatasi, 
pengaturan diet, pedoman diet, dan upaya untuk mencegah DM.

Penyuluhan mengenai pengetahuan diabetes sebagai dampak tingginya kejadian stunting, angka kejadian diabetes yang tinggi, penatalaksanaan pencegahan diabetes dan bahan makanan yang diperbolehkan, dikurangi dan dihindari juga turut diberikan dalam penyuluhan. Penyuluhan bertujuan untuk penyebarluasan informasi, menanamkan keyakinan dengan memberi kesadaran, pengetahuan, dan pengertian, harapannya peserta mau melakukan perbuatan sesuai anjuran kesehatan (Rahmawati 2019).

Penyuluhan adalah salah satu program pendidikan kesehatan untuk mencegah terjadinya masalah kesehatan, menambah pengetahuan, dan mengubah perilaku secara mandiri agar kualitas hidup lebih sehat (Doringin 2019). Penyuluhan diabetes perlu dilakukan di Dilem. Hal ini disebabkan DM adalah salah satu penyakit tidak menular, penyebab kematian tertinggi $(60 \%)$ di Indonesia (Indarjo et al, 2019). DM disebabkan oleh faktor genetika, lingkungan, gaya hidup (merokok, mengkonsumsi alkohol), pola makan, dan kurangnya aktivitas (Hastuti et al. 2019). Pada penyuluhan di Dilem faktor tersebut juga dijelaskan kepada masyarakat.

Pemilihan metode serta media yang tepat dapat berpengaruh pada keberhasilan kegiatan penyuluhan (Sumarni, Rosidin, \& Sumarna, 2020). Selain mendapatkan materi penyuluhan melalui ceramah, masyarakat juga mendapat media pembelajaran dalam bentuk leaflet. Harapannya leaflet ini dapat dibaca di rumah oleh masyarakat untuk memperkuat retensi dan mengingat kembali materi penyuluhan. Tujuan penyuluhan agar masyarakat mengerti dan memahami DM serta turut aktif melakukan perilaku untuk mencegah DM bagi yang sehat. Jika keluarga atau masyarakat terkena DM melalui penyuluhan ini dapat mengatur diet dan pola makan melalui konsumsi pangan lokal.

Pemilihan media leaflet merujuk pada hasil penelitian Ramadhani et al. (2019), yang menyatakan bahwa penyuluhan dengan ceramah menggunakan media leaflet lebih optimal dalan meningkatkan pengetahuan, sikap seseorang dibandingkan tanpa mengunakan media apapun. Leaflet merupakan salah satu media edukasi kesehatan yang memiliki berbagai kelebihan. Berbagai kelebihannya antara lain mudah disimpan, ekonomis, berfungsi sebagai pengingat bagi sasaran, lebih singkat, padat dan mudah dipahami oleh sasaran, serta lebih efektif digunakan untuk sasaran dengan berbagai tingkatan pendidikan mulai dari yang tingkat pendidikan rendah sampai tingkat pendidikan tinggi (Ramadhani et al. 2019).

Pada leaflet juga tercantum nomor HP dosen Gizi Klinik STIKes WCH Malang, sebagai salah satu konsultan Gizi yaitu ibu Choirun Nissa, S.Gz. M. Biomed. Harapannya masyarakat dapat berkonsultasi gizi melalui media sms atau WA (WhatsApp). Penyuluhan dengan metode ceramah, media leaflet berpengaruh terdahap pengetahuan (Rahmawati 2019). Pencegahan penyakit DM terbukti efektif ketika diintervensi dengan pendidikan kesehatan, misalnya penyuluhan. Hal ini sesuai dengan penelitian Susena et al (2019) dan Indarjo et al (2019), yang menyatakan bahwa penyuluhan dengan metode ceramah dapat meningkatkan pengetahuan, sikap, dan tindakan atau perilaku masyarakat.

Hasil pengabdian ini menunjukkan bahwa pendidikan kesehatan dengan metode ceramah dan media leaflet terbukti mampu meningkatkan pengetahuan masyarakat Dilem (Gambar 1). Metode pendidikan kesehatan masyarakat secara masal dapat dilakukan dengan ceramah. Pendidikan kesehatan berfungsi untuk memberikan informasi tentang cara mencegah penyakit (Notoatmodjo, 2005). Hal ini sesuai dengan hasil penelitian (Noor, et al., 2015), yang menyatakan bahwa metode ceramah dapat meningkatkan kemampuan memori. Pada dasarnya pendidikan kesehatan bertujuan untuk meningkatkan pengetahuan. Pendidikan kesehatan diharapkan mampu merubah sikap, dan perilaku untuk memelihara kesehatan (Purba dan Simanjuntak 2018). Kegiatan pengabdian masyarakat yang 
dilakukan di Dilem, bertujuan untuk menyebarkan pesan kesehatan dan pentingnya kesehatan, sehingga masyarakat menjadi sadar dan tahu, selanjutnya dapat berperilaku hidup sehat.

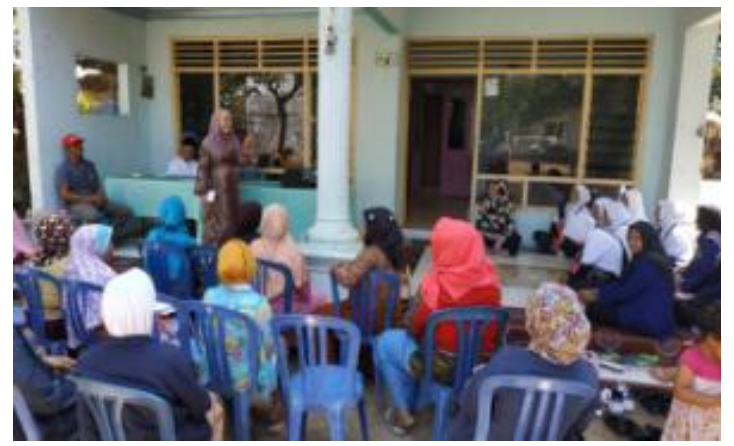

Gambar 1. Penyuluhan di Dilem, Kepanjen

Hal ini berbeda dengan penelitian Juniati dan Widianti (2015), yang menyatakan bahwa metode ceramah kurang efektif meningkatkan pengetahuan. Hal ini dapat dipahami bahwa pengetahuan tidak hanya dipengaruhi oleh metode pembelajaran semata, tetapi juga faktor masyarakat, fasilitator, lingkungan fisik, dan media pembelajaran. Keberhasilan penyuluhan dipengaruhi oleh faktor persiapan, penguasaan materi, bahasan suara, penampilan dan intensitas intervensi penyuluhan (Ramadhani et $a l$, 2019). Durasi penyuluhan yang efektif sekitar 2,5 jam, disertai follow up (Febriani et $a l, 2019)$. Pada kegiatan penyuluhan DM yang dilakukan sekitar 3 jam, dengan follow up melalui pesan WhatsApp. Selain durasi waktu penyuluhan, faktor lain yang berpengaruh menurut Kusyadi et al (2019), antara lain parsitipasi akstif dari peserta, penyampaian materi secara konkrit, dan pendampingan pasca pelatihan.

\section{SIMPULAN}

Kesimpulan dari kegiatan pengabdian kepada masyarakat yaitu edukasi tentang pencegahan penyakit DM terbukti efektif dalam meningkatkan pengetahuan masyarakat. Tingkat pengetahuan masyarakat tentang pencegahan DM melalui konsumsi makanan lokal, diharapkan mampu menekan prevalensi DM di Desa Dilem.

\section{UCAPAN TERIMAKASIH}

Saran-saran untuk untuk penelitian lebih lanjut untuk meneliti sikap dan perilaku masyarakat setelah meningkatnya tingkat pengetahuan masyarakat. Penulis mengucapkan terima kasih kepada masyarakat Desa Dilem, Bapak RT dan Takmir Masjid yang telah berpartisipasi dalam kegiatan pengabdian kepada masyarakat.

\section{DAFTAR PUSTAKA}

Doringin, SV. Engkeng S, Mandagi C. 2019. Pengaruh Penyuluhan Kesehatan Terhadap Pengetahuan dan Sikap Tentang Bahaya Merokok Pada Pelajar di SMA Katolik St. Thomas Aquino Manado. Panglima Sehat, 7, 46-52.

Febriani Z, Kumalasari D., Triman A., Fourianalistyawati E. 2019. Pelatihan Mindful Parenting Bagi Ibu Dengan Balita di Cempaka Putih. Jurnal ABDIMAS Unmer Malang. 4, 1-7.

Hastuti M, Rochadi K., Sudaryati E. 2019. Perbandingan Media Audiovsual dan Ceramah Terhadap Sikap Siswa Tentang Pentingnya Konsumsi Sayur dan Buah. Jurnal JUMANTIK, 4 (2), 1-11.

Indarjo, S., Hermawati, B. Nugraha E. 2019. Upaya Pelatihan Pos Pembinaan Terpadu Penyakit Tidak Menular (Posbindu PTM) pada Kader Posyandu di Desa Kalikayen, Kec. Ungaran Timur, Kab. Semarang. Abdimas Jurnal Pengabdian Kepada Masyarakat. ABDIMAS, 23 (2), 134-138.

Juniati, E. \& Widianti, T. 2015. Pengembangan Buku Saku Berbasis Mind Mapping Dan Multiple Intelligences Materi Jamur Di Sma Negeri 1 Slawi. Unnes Journal of Biology Education, (Online), 4 (1): 1-8. (http://journal. unnes.ac.id/sju/index.php/ujbe/article/vi ew/5232), diakses 10 Novemner 2015.

Kusyandi H, Merdekawati A, Kusumawardani W. 2019. Pelatihan dan Pendampingan Kelompok Mitra PKM di Desa Leseng, Kecamatan Moyo Hulu, Kabupaten 
Sumbawa. Jurnal Ilmiah Pengabdian kepada Masyarakat, 5 (2), 96102Puskesmas Kepanjen Kabupaten Malang. 2018. Data Dasar Puskesmas Kepanjen Kabupaten Malang Tahun 2018.

Noor, Z.A., Mulyani, S. \& Masykuri, M. 2015. Penggunaan Model Pembelajaran Team Assisted Individualization (Tai) Dilengkapi Buku Saku Dan Papan Karbon Untuk Meningkatkan Kemampuan Memori Dan Prestasi Belajar Siswa Pada Materi Senyawa Hidrokarbon Kelas XI Mia Semester Gasal SMA Batik 1 Surakarta Tahun Pelajaran 2014/2015. Jurnal Pendidikan Kimia, (Online), 4 (2): 130-136, (http://jurnal.fkip.uns.ac.id/index.

php/kimia), diakses 25 Februari 2015.

Notoatmodjo, S. 2005. Promosi Kesehatan. Jakarta: Rineka CiptaRiset Kesehatan Dasar (Riskesdas). 2013. Badan Penelitian dan Pengembangan Kesehatan Kementerian RI tahun 2013. Diakses: 19 Oktober 2014, dari http://www.depkes.go.id/resources/dow nload/general/Hasil\%20Riskes das\%20 2013.pdf

Purba AET dan Simanjuntak, EH. 2018. Efektivitas Pendidikan Kesehatan Sadari Terhadap Peningkatan Pengetahuan dan Sikap WUS Tentang Deteksi Dini Kanker Payudara. Jurnal Bidan Komunitas, 3, 160-166.

Rahmawati, A. 2019. Pengaruh Penyuluhan Kesehatan Terhadap Pengetahuan Siswa Tentang Obesitas Pada Remaja di Madrasah Aliyah Negeri 1 Indramayu. HIBUALAMO. Seri Ilmu-ilmu Alam dan Kesehatan, 3, 1-6.

Ramadhanti CA, Adespin DA, Julianti HP. 2019. Perbandingan Penggunaan Metode Penyuluhan dengan dan Tanpa Media Leaflet Terhadap Pengetahuan dan Sikap Ibu Tentang Tumbuh Kembang Balita. JURNAL KEDOKTERAN DIPONEGORO, 8 (1), 5-17.

Riset Kesehatan Dasar (Riskesdas). 2018. Badan Penelitian dan Pengembangan
Kesehatan Kementerian RI tahun 2018. Diakses: 16 September 2020, dari https://kesmas.kemkes.go.id/assets/uplo ad/dir_519d41d8cd98f00/files/Hasilriskesdas-2018_1274.pdf

Sumarni, N., Rosidin, U., \& Sumarna, U. (2020). Penyuluhan Kesehatan tentang Jajanan Sehat di Sekolah Dasar Negeri Jati III Tarogong Kaler Garut. Jurnal Kumawula: Jurnal Pengabdian Kepada Masyarakat, 3(2), 289-297. Diakses dari http://jurnal.unpad.ac.id/kumawula/index

Susena E, Ratnawati AY, Susanto E. 2019. Pelatihan Sistem Informasi Manajemen Pendataan Industri Kecil dan Menengah (SIM-IKM) di Dinas Perindustrian dan Perdagangan Kabupaten Sragen. JURNAL PENGABDIAN KEPADA MASYARAKAT DIKEMAS, 3 (1), 1-6. 